\title{
Effect of previous slurry ice treatment on the quality of cooked sardine (Sardina pilchardus)
}

\author{
Vanesa Losada ${ }^{1}$, Jorge Barros-Velázquez ${ }^{2}$, José M. Gallardo ${ }^{1}$ and \\ Santiago P. Aubourg, ${ }^{1, *}$
}

${ }^{1}$ Department of Food Technology, Instituto de Investigaciones Marinas (CSIC). Eduardo Cabello 6, 36208 Vigo (Spain).

${ }^{2}$ Department of Analytical Chemistry, Nutrition and Food Science, College of Veterinary Sciences, Universidad de Santiago de Compostela, 27002 Lugo (Spain).

*Correspondent: Fax: +34 986 292762; e-mail: saubourg@iim.csic.es 


\begin{abstract}
The use of slurry ice was evaluated as a technological treatment prior to cooking processing of fish. Thus, sardine (Sardina pilchardus) was stored in slurry ice for 2, 5 and 8 days. At such times, sardine specimens were taken and subjected to steam cooking, and the results were compared with those from a parallel control batch previously stored in flake ice. Quality assessment of lipid damage in cooked fish was performed by measuring the formation of free fatty acids, peroxides, thiobarbituric acidreactive substances and interaction compounds. The volatile amines -total and trimethylamine- assessment was also carried out. A significant $(\mathrm{p}<0.05)$ inhibition of lipid damage -peroxides and fluorescent compounds assessment- and trimethylamine formation was observed in cooked sardine as a consequence of the preliminary treatment in slurry ice. This work opens the way to the use of slurry ice as a preliminary treatment of fish material prior to its thermal processing.
\end{abstract}

Running title: Slurry ice and cooked sardine quality

$\underline{\text { Key words: }}$ Sardine, Chilling, Slurry ice, Cooking, Damage, Quality 


\section{INTRODUCTION}

The thermal processing of aquatic food products at moderate temperatures improves their hygiene status and shelf life through the destruction of pathogenic microorganisms and the inactivation of undesirable enzymes. In addition, thermal processes such as cooking enhance the flavour and taste of fish, also inducing a loss of water prior to canning [1-3]. However, owing to the thermal sensitivity of a broad number of fish constituents and nutrients several detrimental effects due to cooking have been reported:

i.e., heat degradation of nutrients, oxidation of vitamins and lipids, leaching of watersoluble vitamins, minerals and proteins, and toughening and drying of sensitive protein tissues $[4,5]$.

Most of the quality problems found in thermally processed fish products are directly related to the initial quality of the fresh raw material, which declines continuously postmortem during its refrigerated storage. As a consequence of this, efficient storage techniques for the refrigeration of fish material must be employed to reduce postmortem quality losses before cooking is carried out. In this sense, among the different handling systems for the preservation of fish material, traditionally flake icing [6], refrigerated sea water [7], immersion in brine solutions [8], or chemical additives [9, 10] have been considered.

The introduction of refrigeration and storage systems based on slurry ice -also known as fluid ice, slush ice, flow ice or liquid ice- has afforded several advantages as compared to traditional flake ice. Among others are (i) sub-zero storage temperature, (ii) faster chilling rates due to the higher heat exchange power of slurry ice, (iii) less physical damage caused to the fish surface due to its microscopic spherical crystals, and (iv) the prevention of dehydration events due to full coverage of the fish surface [11- 
13]. Along this line, recent studies have reported significant inhibitory effects of slurry ice on microbiological and biochemical mechanisms responsible for fish spoilage, as compared to traditional flake ice. This leads to relevant increases in the shelf-life of a broad variety of chilled aquatic food products such as lean fish [14], medium-fat fish [15], fatty fish [16, 17] and crustaceans [18, 19].

The present study was initially based on the advantages reported for aquatic food products subjected to refrigerated storage in slurry ice, the main goal being to explore the potential advantages of such storage as preliminary treatment prior to the cooking of the fish material. Sardine (Sardina pilchardus) was selected for this study owing to its relevance as a thermally processed product of the fish industry [20]. Thus, we compared the chilling and storage of sardine in slurry ice with that employing traditional flake icing as a preliminary treatment prior to thermal processing of the fish by cooking. The effects of the preliminary storage systems considered on the biochemical quality of such cooked fish products are discussed.

\section{MATERIALS AND METHODS}

\section{Preliminary refrigeration and storage systems}

In this work, a slurry ice prototype (FLO-ICE ${ }^{\mathrm{TM}}$, Kinarca S.A.U., Vigo, Spain) was used. The composition of the slurry ice binary mixture was $40 \%$ ice/60\% water, prepared from filtered seawater with 3.3\% salinity. The temperature of the slurry ice mixture was adjusted to $-1.5^{\circ} \mathrm{C}$. The average temperature of the specimens processed in slurry ice was in the range of -1.0 to $-1.5^{\circ} \mathrm{C}$. Flake ice was prepared with an Icematic F100 Compact device (Catelmac Spa, Castelfranco, Italy). The temperature of the flake 
ice was $+0.5^{\circ} \mathrm{C}$. The average temperature of the specimens stored in flake ice was in the range of $+0.5^{\circ} \mathrm{C}$ to $+1.0^{\circ} \mathrm{C}$. Fish specimens were placed under slurry ice or flake ice conditions at a 1:1 fish to ice ratio, and stored in a refrigerated room at $+2^{\circ} \mathrm{C}$. When required, the flake ice and the slurry ice mixture were renewed.

\section{Fish material and sampling}

Sardine (Sardina pilchardus) specimens were caught on September 2005 near the Galician Atlantic coast (North-western Spain) and transported on ice to the laboratory six hours after the catch. The length of the specimens was in the $16-21 \mathrm{~cm}$ range and average weight was $90 \mathrm{~g}$. The fish specimens were neither headed nor gutted and were directly packed with slurry ice or flake ice by placing the mixtures into polystyrene boxes provided with holes for drainage. Three different groups $(n=3)$ were used for each preliminary icing treatment and were analysed separately along the whole experimental study. Fish specimens were taken for cooking treatment on the starting day (day 0, no previous chilling) and on days 2, 5 and 8 days of chilled storage under both icing conditions and were subjected to cooking.

\section{Technical conditions of the cooking process}

Chilled sardine specimens were steam-cooked in an autoclave at the pilot plant of the Institute for Marine Research (Vigo, Spain). The autoclave temperature was in the range of $102-103^{\circ} \mathrm{C}$, the thermal processing of samples being maintained until the backbone temperature reached $65^{\circ} \mathrm{C}$ [21]. Then, fish were cooled to room temperature $\left(14^{\circ} \mathrm{C}\right)$ for about 2 hours, and the specimens were headed and eviscerated so that the white muscle could be readily separated and subjected to biochemical analyses. 


\section{Compositional analyses}

Moisture contents were determined by weight differences between the homogenised fish muscle (1-2 g) before and after heating at $105^{\circ} \mathrm{C}$ for $24 \mathrm{~h}$. The results were expressed as g water/100 g muscle.

The lipid fraction was extracted according to the Bligh and Dyer [22] method. The results are expressed as g lipids/100 g muscle.

$\mathrm{NaCl}$ contents were determined after boiling portions of fish muscle in the presence of $\mathrm{HNO}_{3}$, followed by the addition of excess $0.1 \mathrm{~N} \mathrm{AgNO}_{3}$ and the titration of nonneutralised silver nitrate with $0.1 \mathrm{~N} \mathrm{NH}_{4} \mathrm{SCN}$ [23]. The results are expressed as $\mathrm{g}$ $\mathrm{NaCl} / 100 \mathrm{~g}$ muscle.

\section{$\underline{\text { Analyses of volatile amines }}$}

Total volatile base-nitrogen (TVB-N) values were measured with the Antonacopoulos [24] method, with some modifications. Briefly, fish muscle (10 g) was extracted with $6 \%(\mathrm{w} / \mathrm{v})$ perchloric acid and brought up to $50 \mathrm{ml}$, determining the TVB$\mathrm{N}$ content-after steam-distillation of the acid extracts rendered alkaline to $\mathrm{pH} 13$ with $2 \%(\mathrm{w} / \mathrm{v}) \mathrm{NaOH}$ - by titration of the distillate with $10 \mathrm{mM} \mathrm{HCl}$. The results are expressed as mg TVB-N/100 g muscle.

Trimethylamine-nitrogen (TMA-N) values were determined by means of the picrate method, as previously described [25]. This involves the preparation of a 5\% (w/v) trichloroacetic acid extract of fish muscle. The results are expressed as mg TMA-N/100 g muscle. 


\section{Analyses of lipid damage}

Lipid hydrolysis was estimated by measuring the free fatty acid (FFA) content in the lipid extract with the Lowry and Tinsley [26] method, which is based on the formation of a complex with cupric acetate-pyridine. The results are expressed as g FFA/100 g muscle.

Primary lipid oxidation was determined by means of the peroxide value (PV) according to the ferric thiocyanate method [27]. The results are expressed as meq active oxygen/kg lipids.

Secondary lipid oxidation was investigated using the thiobarbituric acid index (TBA-i) according to the method of Vyncke [28]. The results are expressed as mg malondialdehyde/kg muscle.

Tertiary lipid oxidation was determined by measuring the formation of fluorescent compounds with a Perkin Elmer LS 3B fluorimeter at 393/463 nm and 327/415 nm, as previously described [29]. The relative fluorescence (RF) was calculated as follows: RF $=\mathrm{F} / \mathrm{F}_{\mathrm{st}}$, where $\mathrm{F}$ is the fluorescence measured at each excitation/emission maximum, and $\mathrm{F}_{\mathrm{st}}$ is the fluorescence intensity of a quinine sulphate solution $(1 \mu \mathrm{g} / \mathrm{ml}$ in $0.05 \mathrm{M}$ $\mathrm{H}_{2} \mathrm{SO}_{4}$ ) at the corresponding wavelength. The fluorescence ratio (FR) was calculated as the ratio between the two $R F$ values: $F R=R F_{393 / 463 n m} / R_{327 / 415 n m}$. In all cases, the FR value was determined in the lipid extract.

\section{$\underline{\text { Statistical analyses }}$}

The SPSS software (SPSS Inc., Chicago, IL, USA) was used to explore the statistical significance of the differences observed between preliminary slurry ice and flake ice storage systems in their corresponding cooked samples. Statistical analyses included the performance of multivariate contrasts and multiple comparisons with the 
Scheffé and Tukey tests. The data obtained from different measurements were subjected to one-way analysis of variance; comparison of means was performed using a leastsquares difference (LSD) method [30]. In all cases a confidence interval at the 95\% level $(\mathrm{p}<0.05)$ was considered.

\section{RESULTS AND DISCUSSION}

\section{Compositional analyses}

The moisture content of the cooked sardine specimens ranged from 66-69\% (Table 1). Remarkably, a detailed comparison between cooked fish samples that had previously been chilled under each icing system did not reveal significant differences ( $p>0.05$ ). As a consequence, no relevant effect of preliminary storage in slurry on the moisture content of the cooked fish material could be considered. When compared to the cooked sardine specimens that had not undergone any previous chilled storage (day 0), a significant decrease in the moisture content was observed in the cooked sardine specimens previously stored for 8 days in either of the two storage systems. Such a decrease can be explained in terms of protein degradation in sardine muscle along refrigerated storage, this leading to a decreasing water holding capacity (WHC) of the myofibrillar protein fraction. This reduction in the WHC of that protein fraction may facilitate the loss of water during thermal processing, as reported previously [31, 32]. Thus, the results obtained in our study are in agreement with previous works reporting progressive losses in fish moisture along the chilling time [3].

The lipid content of the cooked sardine specimens ranged from 4.5-6.4\% (Table 1) and increased in both batches with the time of chilled storage. This result should be 
explained as being a direct consequence of the above-reported water loss, as previously reported by other authors [33, 34]. As in the case of the moisture content, no significant ( $>0.05$ ) differences were observed in the lipid content of the cooked sardine samples deriving from preliminary storage in flake ice or slurry ice.

In contrast, the $\mathrm{NaCl}$ content in sardine muscle exhibited an increasing value in cooked sardine specimens that had previously been stored in slurry ice (Table 1). This can be explained as being due to the presence of $\mathrm{NaCl}$ in the ice slurry system $[15,17]$. Thus, a significantly $(\mathrm{p}<0.05)$ higher $\mathrm{NaCl}$ content in cooked sardine muscle was determined in the slurry ice batch as compared to that subjected to preliminary flake icing. Despite, it should be stressed that the $\mathrm{NaCl}$ concentrations determined in cooked sardines after 8 days of storage in slurry ice were found to be much lower than those described for fish material subjected to refrigeration in seawater [35], salting [36, 37] or salting followed by smoking [38].

\section{Analyses of volatile amines}

The results of TVB-N analyses are shown in Figure 1. No significant differences ( $>0.05$ ) deriving from the different preliminary storage systems were found in the muscle of cooked sardine specimens. In this sense, a two-day storage under either of the preliminary icing conditions tested involved significant increases $(\mathrm{p}<0.05)$ of TVB-N in cooked sardine. However, lengthening storage in slurry ice up to 8 days was not accompanied by any significant $(\mathrm{p}>0.05)$ additional formation of TVB-N, while a significant $(\mathrm{p}<0.05)$ increase in this parameter was observed in the batch preliminarily stored for up to 8 days in flake ice.

TMA-N contents are shown in Figure 2. TMA-N concentrations in cooked sardine muscle increased as the length of preliminary chilled storage increased in both icing 
conditions. Remarkably, a significantly higher $(\mathrm{p}<0.05)$ formation of TMA-N was observed in cooked sardine previously stored under flake ice conditions (Figure 2). Accordingly, an inhibitory effect of slurry ice can be concluded for the formation of TMA-N in cooked sardine. This result may be of relevance not only for cooked sardine, but also for other fatty fish species subjected to thermal processing, because TMA-N is one of the main compounds involved in off-odour production in spoiled fish [39, 40].

In the actual research, TMA-N assessment has shown to be a more accurate index than TVB-N value. This can be explained by the fact that the later quantifies a wide range of basic volatile compounds $\left(\mathrm{NH}_{3}\right.$, methylamine, dimethylamine, trimethylamine, etc.) produced by different damage pathways, while TMA-N assessment accounts only for the trimethylamine oxide breakdown, being produced in the present study during the chilled (bacterial activity) and high temperature (thermal breakdown) treatments.

\section{Analyses of lipid damage}

Lipid hydrolysis was determined by measuring FFA contents (Table 2). FFA formation in thermally processed fish has been recognised to be a result of the breakdown of high-molecular weight (triglycerides and phospholipids, namely) lipids $[33,41]$. In the present work, the assessment of FFA in cooked sardine clearly pointed to increases in this parameter as the time of preliminary chilled storage increased (Table 2). This finding was observed for both storage systems. Thus, no significant $(p>0.05)$ effect of the preliminary storage system on the FFA content of cooked sardine muscle can be concluded.

Primary and secondary lipid oxidation events in cooked sardine muscle were determined by means of the peroxide value (PV) and the formation of thiobarbituric acid reactive substances (TBARS), respectively (Table 2). A detailed comparison 
between both icing conditions clearly revealed a significantly $(\mathrm{p}<0.05)$ higher degree of peroxide formation for cooked fish previously stored under flake ice conditions. Accordingly, an inhibitory effect of the preliminary slurry ice treatment on primary lipid oxidation events can be concluded. Moreover, while the PV in cooked sardine muscle exhibited a remarkable increase along the time of preliminary storage in flake ice, this was not the case for specimens stored in slurry ice.

Secondary lipid oxidation was measured by means of TBARS formation (Table 2). An important development of such assessment has been previously observed in other cooked fish species [42, 43]. In our study, no differential effect of the preliminary slurry ice treatment can be concluded ( $>0.05)$, although higher mean TBARS values were obtained in cooked sardine specimens previously stored in flake ice as compared to their counterpart samples processed in slurry ice. For both preliminary storage systems, increases in TBARS were observed as the time of chilled storage progressed (Table 2).

Results obtained on TBARS formation is deemed specially important to the study because of its previously reported close relationship with sensory assessment [44, 45]. Thus, among the different kinds of compounds produced as a result of lipid oxidation, secondary ones are considered the chief compounds responsible for oxidised flavours.

The formation of interaction compounds [46, 47] -also called tertiary oxidation compounds- is the result of the interaction between lipid oxidation compounds and protein-like nucleophilic molecules present in fish muscle. Such oxidation events were studied by means of the fluorescence ratio (FR); the results are shown in Table 2. Thus, comparison between both preliminary chilled storage systems revealed a more reduced development $(\mathrm{p}<0.05)$ of fluorescence in cooked sardine specimens preliminarily stored in slurry ice. From this, an inhibitory effect of such treatment on tertiary oxidation events may be concluded. When compared to cooked fish that had not undergone a 
chilling storage (day 0), both icing conditions did not led to significant increases after 2 and 5 days of storage; however, these values differed significantly when preliminary storage was extended to 8 days, lower FR values being determined in the slurry ice batch than in the flake ice batch.

\section{FINAL REMARKS}

We have previously shown that the use of slurry ice as a chilling and storage system exerts a significant inhibitory effect on the sensory, biochemical and microbiological spoilage mechanisms occurring in fish. In the present work, a newer potential application of slurry ice as a preliminary storage system of sardine prior to its thermal processing by cooking was explored. Previous processing of sardine in slurry ice led to significantly $(\mathrm{p}<0.05)$ less lipid damage as compared to storage in flake ice, as can be concluded from the results obtained in the primary and tertiary oxidation events measured by the PV and FR, respectively. In addition, preliminary treatment in slurry ice elicited a significant $(\mathrm{p}<0.05)$ inhibition of TMA-N formation, indicating a more limited degradation of nitrogen compounds in that batch as compared to counterpart storage in flake ice. As a consequence, when preliminarily stored in slurry ice cooked sardines exhibited a better biochemical quality than when stored in conventional flake ice. The use of slurry ice as a previous step to cooking is advisable for sardine, and may be extended to other fat fish species.

In a previous research [48], the effect of previous slurry ice/flake ice conditions on the quality of canned horse mackerel (Trachurus trachurus) was studied. In such experiment, the different analyses carried out (colour, TBARS, FFA, FR and browning 
assessments and sensory acceptance) on canned fish did not provide significant differences ( $p>0.05)$ as a result of the preliminary icing conditions. Several reasons can be argued to explain different conclusions when compared to the actual ones. First, the canning process provides a strong heat step (sterilisation) not included in the present experiment that can substantially modify the results on quality indices. Second, the existence in the canned product of a coating medium renders it difficult to obtain a profitable application of most indices, as most molecules involved in fish quality loss may be partially lost into the coating medium. Finally, horse mackerel is a medium-fat fish species, so that the lipid damage development should not be as important to fish quality loss as in the case of a fattier fish species as sardine.

\section{ACKNOWLEDGEMENTS}

The authors thank Mr. Marcos Trigo and Mr. Roi González Vázquez for technical assistance, and KINARCA S.A.U. for providing the slurry ice equipment. This work was supported by a project granted by the Secretaría Xeral de $I+D$ from the Xunta de Galicia (Spain) (Project PGIDIT 02 RMA 18E). 


\section{REFERENCES}

1. Aitken A, Connell J (1979) Fish. In: Priestley R (ed) Effects of heating on food stuffs. Applied Science Publishers Ltd, London (UK), pp 219-254

2. McLay R (1982) Canning. In: Aitken, Mackie I, Merritt J, Windsor M (eds) Fish: Handling and processing. Ministry of Agriculture, Fisheries and Food. Torry Research Station, Edinburgh (Scotland, UK), pp 115-125

3. Joshi V, Saralaya K (1982) Mysore J Agric Sci 16: 338-345

4. Pigott G, Tucker B (1987) Food Rev Int 3: 105-138

5. Aubourg S (2001) Food Sci Technol Int 7: 199-205

6. Whittle K, Hardy R, Hobbs G (1990) Chilled fish and fishery products. In: Gormley T (ed) Chilled Foods. The state of the art. Elsevier Applied Science, New York (USA), pp 87-116

7. Kraus L (1992) Refrigerated sea water treatment of herring and mackerel for human consumption. In: Burt J, Hardy R, Whittle K (eds) Pelagic fish. The resource and its exploitation. Fishing News Books, Aberdeen, Scotland (UK), pp 73-81

8. Xiong S, Xiong Y, Blanchard S, Wang B, Tidwell J (2002) Int J Food Sci Technol 37: 291-296

9. Toledo-Flores L, Zall R (1992) Methods for extending the storage life of fresh tropical fish. In: Flick G, Martin R (eds) Advances in seafood biochemistry. Composition and quality. Technomic Publishing Company, Lancaster, Pa (USA), pp 233-243

10. Hwang K, Regenstein J (1995) J Aquat Food Prod Technol 4: 19-30

11. Chapman L (1990) Aust Fish, July: 16-19

12. Harada K (1991) Aust Fish, February: 28-30 
13. Piñeiro C, Barros-Velázquez J, Aubourg S (2004) Trends Food Sci Technol 15: $575-582$

14. Losada V, Piñeiro C, Barros-Velázquez J, Aubourg S (2004) Eur Food Res Technol 219: $27-31$

15. Losada V, Piñeiro C, Barros-Velázquez J, Aubourg S (2005) Food Chem 93: 619625

16. Price R, Melvin E, Bell J (1991) J Food Sci 56: 318-321

17. Losada V, Barros-Velázquez J, Gallardo J, Aubourg S (2004) Eur J lipid Sci Technol 106: 844-850

18. Chinivasagam H, Bremner H, Wood A, Nottingham S (1998) Int J Food Microb 42: 45-55

19. Huidobro A, López-Caballero M, Mendes R (2002) Z Lebensm Unters Forsch 214: $469-475$

20. FAO Inform (2005) Fishery statistics. In: Food and Agriculture Organization of the United Nations, Rome. Yearbook 2003, vol 97, p 173

21. Pérez-Martín R, Banga J, Sotelo C, Aubourg S, Gallardo J (1989) J Food Eng 10: 83-95

22. Bligh E, Dyer W (1959) Can J Biochem Physiol 37: 911-917

23. AOAC (1990) Official methods for analysis of the Association of Analaytical Chemistry. $15^{\text {th }}$ ed, p 870

24. Antonacopoulos N (1960) Z Lebensm Unters Forsch 13: 113-160

25. Tozawa H, Erokibara K, Amano K (1971) Proposed modification of Dyer's method for trimethylamine determination in codfish. In: Kreuzer R (ed) Fish inspection and quality control. Fishing News Books, London (UK), pp 187-190

26. Lowry R, Tinsley I (1976) J Am Oil Chem Soc 53: 470-472 
27. Chapman R, McKay J (1949) J Am Oil Chem Soc 26: 360-363

28. Vyncke W (1970) Fette Seifen Anstrichm 72: 1084-1087

29. Aubourg S (1999) J Amer Oil Chem Soc 76: 409-419

30. Statsoft (1994) Statistica for macintosh; Statsoft and its licensors, Tulsa, Oklahoma (USA)

31. Seet S, Brown D (1983) J Food Sci 48: 288-289

32. Castrillón A, Navarro P, García-Arias M (1996) J Food Sci 61: 1250-1253

33. Gallardo J, Aubourg S, Pérez-Martín R (1989) J Agric Food Chem 37: 1060-1064

34. García-Arias M, Sánchez-Muniz J, Castrillón A, Navarro P (1994) J Food Comp Anal 7: 119-130

35. Smith J, Hardy R, McDonald I, Templeton J (1980) J Sci Food Agric 31: 375-385

36. Srikar L, Khuntia B, Reddy G, Srinivasa B (1993) J Sci Food Agric 63: 319-322

37. Thorarinsdóttir K, Arason S, Geirsdóttir M, Bogason S, Kristbergsson K (2002) Food Chem 77: 377-385

38. Jittinandana S, Kenney P, Slider S, Kiser R (2002) J Food Sci 67: 2095-2099

39. Gallardo J, Pérez-Martín R, Franco J, Aubourg S, Sotelo C (1990) Int J Food Sci Technol 25: 78-81

40. Olafsdóttir G, Martinsdóttir E, Oehlenschläger J, Dalgaard P, Jensen B, Undeland I, Mackie I, Henehan G, Nielsen J, Nilsen H (1997) Trends Food Sci Technol 8: 258-265

41. Medina I, Sacchi R, Aubourg S (1994) J Amer Oil Chem Soc 71: 479-482

42. Tichivangana J, Morrisey P (1982) Irish J Food Sci Technol 6: 157-163

43. Yamamoto Y, Imose K (1989) J Nutrit Sci Vitam 35: 39-47

44. Kurade S, Baranowski J (1987) J Food Sci 52: 300-302, 311 
45. White P (1994) Conjugated diene, anisidine value and carbonyl value analyses. In: Warner K, Eskin M (eds) Methods to assess quality and stability of oils and fatcontaining foods. AOCS Press, Champaign, Illinois (USA), pp 159-178

46. Pokorný J (1981) Prog Food Nutr Sci 5: 421-428

47. Howell N (1995) Interaction of proteins with small molecules. In: Gaonkar A (ed) Ingredient interactions - Effects on food quality. Marcel Dekker, New York (USA), pp 269-289

48. Losada V, Lehmann I, Schubring R, Aubourg S (2004) Effect of different previous icing conditions on sensory, physical and chemical quality of canned horse mackerel (Trachurus trachurus). In: Rehbein H, Karl M, Manthey-Karl M, Oehlenschläger J, Schubring $\mathrm{R}$ (eds) Proceedings of the $34^{\text {th }}$ WEFTA Conference. German Federal Research Centre for Nutrition and Food, Department for Fish Quality, Hamburg (Germany), pp. 119-121 


\section{FIGURE LEGENDS}

Figure 1: Comparative evolution of total volatile base-nitrogen (TVB-N)* contents in cooked sardine subjected to preliminary chilled storage under slurry ice and flake ice

* Mean values of three independent determinations $(n=3)$ are presented. Standard deviations are denoted by bars.

Figure 2: Comparative evolution of trimethylamine-nitrogen (TMA-N)* contents in cooked sardine subjected to preliminary chilled storage under slurry ice and flake ice

* Mean values of three independent determinations $(n=3)$ are presented. Standard deviations are denoted by bars. 


\section{TABLE 1}

Comparative evolution of compositional parameters* in cooked sardine subjected to preliminary chilled storage under flake ice and slurry ice

\begin{tabular}{|c|c|c|c|c|c|c|}
\hline $\begin{array}{c}\text { Preliminary } \\
\text { chilling time } \\
\text { (days) }\end{array}$ & \multicolumn{2}{|c|}{ Moisture } & \multicolumn{2}{c|}{ Lipids } & \multicolumn{2}{c|}{ NaCl } \\
\cline { 2 - 7 } & Flake Ice & Slurry Ice & Flake Ice & Slurry Ice & Flake Ice & Slurry Ice \\
\hline 0 & $68.99 \mathrm{~b}$ & $\begin{array}{c}68.99 \mathrm{~b} \\
(0.25)\end{array}$ & $\begin{array}{c}4.52 \mathrm{a} \\
(0.15)\end{array}$ & $\begin{array}{c}4.52 \mathrm{a} \\
(0.15)\end{array}$ & $\begin{array}{c}0.05 \mathrm{a} \\
(0.01)\end{array}$ & $\begin{array}{c}0.05 \mathrm{a} \\
(0.01)\end{array}$ \\
\hline 2 & $68.60 \mathrm{~b}$ & $68.36 \mathrm{ab}$ & $5.26 \mathrm{ab}$ & $5.72 \mathrm{~b}$ & $0.05 \mathrm{a}$ & $0.06 \mathrm{a}$ \\
& $(0.39)$ & $(0.53)$ & $(0.42)$ & $(0.41)$ & $(0.01)$ & $(0.02)$ \\
\hline 5 & $67.80 \mathrm{ab}$ & $68.75 \mathrm{~b}$ & $6.33 \mathrm{~b}$ & $5.52 \mathrm{ab}$ & $0.11 \mathrm{~b}$ & $0.12 \mathrm{~b}$ \\
& $(1.01)$ & $(1.40)$ & $(1.01)$ & $(0.76)$ & $(0.00)$ & $(0.02)$ \\
\hline 8 & $66.52 \mathrm{a}$ & $67.18 \mathrm{a}$ & $5.83 \mathrm{ab}$ & $5.95 \mathrm{~b}$ & $0.06 \mathrm{a}$ & $0.28 \mathrm{c}$ \\
& $(1.16)$ & $(0.59)$ & $(1.32)$ & $(0.65)$ & $(0.01)$ & $(0.01)$ \\
\hline
\end{tabular}

* Mean values of three independent determinations $(n=3)$ are presented. Standard deviations are indicated in brackets. For each column, values followed by different letters denote significant differences $(\mathrm{p}<0.05)$ as a result of chilling time. 


\section{TABLE 2}

\section{Comparative evolution of lipid damage indices* in cooked sardine subjected to preliminary chilled storage under flake ice and slurry ice**}

\begin{tabular}{|c|c|c|c|c|c|c|c|c|}
\hline \multirow{2}{*}{$\begin{array}{l}\text { Preliminary } \\
\text { chilling } \\
\text { time (days) }\end{array}$} & \multicolumn{2}{|c|}{ FFA } & \multicolumn{2}{|c|}{ PV } & \multicolumn{2}{|c|}{ TBA-i } & \multicolumn{2}{|c|}{ FR } \\
\hline & $\begin{array}{l}\text { Flake } \\
\text { Ice }\end{array}$ & $\begin{array}{l}\text { Slurry } \\
\text { Ice }\end{array}$ & $\begin{array}{l}\text { Flake } \\
\text { Ice }\end{array}$ & $\begin{array}{l}\text { Slurry } \\
\text { Ice }\end{array}$ & $\begin{array}{l}\text { Flake } \\
\text { Ice }\end{array}$ & $\begin{array}{l}\text { Slurry } \\
\text { Ice }\end{array}$ & $\begin{array}{l}\text { Flake } \\
\text { Ice }\end{array}$ & $\begin{array}{c}\text { Slurry } \\
\text { Ice }\end{array}$ \\
\hline 0 & $\begin{array}{c}0.14 \mathrm{a} \\
(0.03)\end{array}$ & $\begin{array}{l}0.14 \mathrm{a} \\
(0.03)\end{array}$ & $\begin{array}{l}2.02 \mathrm{a} \\
(0.11)\end{array}$ & $\begin{array}{c}2.02 \mathrm{a} \\
(0.11)\end{array}$ & $\begin{array}{l}0.66 \mathrm{a} \\
(0.04)\end{array}$ & $\begin{array}{l}0.66 \mathrm{a} \\
(0.04)\end{array}$ & $\begin{array}{l}0.34 \mathrm{a} \\
(0.02)\end{array}$ & $\begin{array}{c}0.34 \mathrm{a} \\
(0.02)\end{array}$ \\
\hline 2 & $\begin{array}{c}0.13 \mathrm{a} \\
(0.05)\end{array}$ & $\begin{array}{c}0.13 \mathrm{a} \\
(0.04)\end{array}$ & $\begin{array}{c}4.21 \mathrm{~b} \\
(1.25)\end{array}$ & $\begin{array}{c}2.63 \mathrm{a} \\
(1.67)\end{array}$ & $\begin{array}{c}1.70 \text { bc } \\
(0.67)\end{array}$ & $\begin{array}{c}0.79 \text { a } \\
(0.27)\end{array}$ & $\begin{array}{c}0.49 \text { a } \\
(0.12)\end{array}$ & $\begin{array}{c}0.48 \mathrm{ab} \\
(0.17)\end{array}$ \\
\hline 5 & $\begin{array}{c}0.20 \mathrm{a} \\
(0.03)\end{array}$ & $\begin{array}{c}0.21 \mathrm{~b} \\
(0.02)\end{array}$ & $\begin{array}{c}3.58 \mathrm{ab} \\
(1.28)\end{array}$ & $\begin{array}{c}2.72 \mathrm{a} \\
(0.40)\end{array}$ & $\begin{array}{c}1.16 \mathrm{ab} \\
(0.17)\end{array}$ & $\begin{array}{l}1.11 \mathrm{a} \\
(0.22)\end{array}$ & $\begin{array}{c}0.46 \text { a } \\
(0.07)\end{array}$ & $\begin{array}{c}0.35 \text { a } \\
(0.03)\end{array}$ \\
\hline 8 & $\begin{array}{c}0.28 \mathrm{~b} \\
(0.05)\end{array}$ & $\begin{array}{l}0.30 \mathrm{c} \\
(0.02)\end{array}$ & $\begin{array}{l}6.80 \mathrm{c} \\
(1.13)\end{array}$ & $\begin{array}{l}3.17 \mathrm{a} \\
(0.54)\end{array}$ & $\begin{array}{l}1.97 \mathrm{c} \\
(0.43)\end{array}$ & $\begin{array}{l}1.67 \mathrm{~b} \\
(0.37)\end{array}$ & $\begin{array}{l}1.24 \mathrm{~b} \\
(0.47)\end{array}$ & $\begin{array}{l}0.56 \mathrm{~b} \\
(0.12)\end{array}$ \\
\hline
\end{tabular}

* Abbreviations: FFA (free fatty acids), PV (peroxide value), TBA-i (thiobarbituric acid index) and FR (fluorescence ratio).

** Mean values of three independent determinations $(n=3)$ are presented. Standard deviations are indicated in brackets. For each column, values followed by different letters denote significant differences $(\mathrm{p}<0.05)$ as a result of chilling time. 